\title{
Influence of large scale oscillations on upwelling-favorable coastal wind off central Chile
}

\author{
David A. Rahn ${ }^{1,2}$ \\ Received 27 April 2012; revised 19 July 2012; accepted 29 August 2012; published 10 October 2012.
}

[1] Along the central coast of Chile is typically equatorward, upwelling-favorable wind associated with the southeast Pacific anticyclone. A coastal low-level jet often develops, and its wind speed is mostly controlled by the meridional pressure gradient. While the low-level jet is a mesoscale feature forced by an interaction between synoptic conditions and coastal topography, regional sea level pressure anomalies are associated with changes of the Antarctic, Madden Julian, and El Niño-Southern Oscillation.

The connection between the alongshore wind and changes to the large-scale circulation is examined and quantified using 31 years of the Climate Forecast System Reanalysis, which resolves coastal features better than previous, coarser analyses. Composites based on each index reveal the modulation of the sea level pressure and significant alongshore wind anomalies of $\pm 0.5-1.5 \mathrm{~m} \mathrm{~s}^{-1}$ that correlate well to meridional surface pressure gradient changes and are centered near $35^{\circ} \mathrm{S}$. Constructive and destructive interference exists between the three indices that either enhance or cancel the alongshore wind anomaly. During favorable upwelling conditions the distribution of meridional wind is generally clustered around positive anomalies with a tail toward negative values, representing a stronger and persistent anticyclone. During unfavorable upwelling conditions the anomalies are generally more normally distributed, representing a weaker anticyclone and the passage of more cyclones.

Citation: Rahn, D. A. (2012), Influence of large scale oscillations on upwelling-favorable coastal wind off central Chile, J. Geophys. Res., 117, D19114, doi:10.1029/2012JD018016.

\section{Introduction}

[2] Over the southeast Pacific (SEP) the circulation is generally dominated by a surface anticyclone that drives low-level equatorward wind along the Chilean coast. Satellitederived surface wind climatologies show a wind speed maximum embedded in the prevailing flow off the Chilean coast between 30 and $35^{\circ} \mathrm{S}$ [Halpern et al., 2002]. This low-level jet (LLJ) has a cross-shore scale $<500 \mathrm{~km}$, exists $60 \%(45 \%)$ of the time during austral spring and summer (winter), generally lasts 3-7 days, and is associated with a cooling of the sea surface through offshore Ekman transport and coastal upwelling [Garreaud and Muñoz, 2005; Renault et al., 2009]. Strong quasi-weekly LLJ episodes are associated with the eastward displacement of the surface anticyclone and the establishment of a coastal trough farther north concomitant with a mid-troposphere ridge axis crossing central Chile and easterly wind down the western slope of the Andes Cordillera.

\footnotetext{
${ }^{1}$ Departamento de Geofísica, Facultad de Ciencias Físicas y Matemáticas, Universidad de Chile, Santiago, Chile.

${ }^{2}$ Now at Atmospheric Science Program, Department of Geography, University of Kansas, Lawrence, Kansas, USA.

Corresponding author: D. A. Rahn, Atmospheric Science Program, Department of Geography, University of Kansas, 1475 Jayhawk Blvd., 201 Lindley Hall, Lawrence, KS 66045-7613, USA. (darahn@ku.edu)

C2012. American Geophysical Union. All Rights Reserved. 0148-0227/12/2012JD018016
}

The topography inhibits cross-shore flow, disrupts a geostrophically balanced zonal wind, produces an enhanced northward sea level pressure (SLP) gradient along the coast, and accelerates the wind northward until it is balanced by turbulent diffusion [Muñoz and Garreaud, 2005]. The wind speed increases with height throughout the marine boundary layer, consistent with a thermal wind equilibrium considering sea surface temperature warming offshore and marine boundary layer depth increasing offshore. The wind speed is closely related to the magnitude of the meridional SLP gradient $\left(\triangle \mathrm{SLP}_{\mathrm{y}}\right.$ ) explaining up to $80 \%$ of the day-to-day variability in central Chile over September-December 2000-2001 [Muñoz and Garreaud, 2005]. Garreaud and Falvey [2009] used monthly (November to February 2000-2005) mean values of wind speed at $33^{\circ} \mathrm{S}, 74^{\circ} \mathrm{W}$ and a $\triangle \mathrm{SLP}_{\mathrm{y}}$ between $38^{\circ}$ and $28^{\circ} \mathrm{S}$ along $74^{\circ} \mathrm{W}$ and found a significant correlation with a fittedline slope of $1 \mathrm{~m} \mathrm{~s}^{-1} \mathrm{hPa}^{-1}$. These results were expanded over longer time periods and over the coasts of Peru and Chile by D. A. Rahn and R. D. Garreaud (A synoptic climatology of the near-surface wind along the west coast of South America, submitted to International Journal of Climatology, 2012) in a synoptic climatology of the alongshore wind (emphasizing strong wind events) that focused on three major upwelling regions and stressed the importance of the alongshore pressure gradient on the coastal wind.

[3] SLP anomalies are also associated with changes in the large-scale atmospheric circulation, not just synoptic 
variability. Over the SEP the most important ones are the Madden Julian Oscillation (MJO), Antarctic Oscillation (AAO), and El Niño-Southern Oscillation (ENSO). Each has its own particular forcing, region of influence, and teleconnections, but each impacts the meteorological conditions over the SEP. It should be noted that these indices represent and quantify oscillatory features in the atmosphere and are not in themselves a cause or forcing mechanism of the large-scale conditions. Most of the LLJ variance is in the sub-monthly time scale with expected weaker signals in the intraseasonal to interannual scales [Rutllant et al., 2004]. For any time scale the fundamental forcing of the LLJ depends on the $\triangle \mathrm{SLP}_{\mathrm{y}}$ near the coast. This relationship diminishes offshore as the topographic influence is reduced and does not break down the geostrophic balance. Because each of these climate indices represents an anomalous state of the general circulation over the SEP, the relationship between each index, $\triangle \mathrm{SLP}_{\mathrm{y}}$, and the alongshore wind speed is explored. A large scale relationship was suggested by Renault et al. [2009], which noted that the synoptic conditions, LLJ, and upwelling activity exhibited linked variability at intraseasonal and interannual time scales. Rutllant et al. [2004] investigated the role of the MJO on the cross-coast SLP gradient and pseudo-windstress at $30^{\circ} \mathrm{S}$. Several authors [e.g., Aceituno, 1988; Montecinos and Gomez, 2010] have investigated the relationship of ENSO and surface wind, but less attention has been given to the AAO and MJO. To establish and quantify the relationship, if any, between the state of the oscillations and the alongshore wind, reanalysis data is composited based on indices of AAO, MJO, and ENSO and changes in the distribution of the alongshore wind are demonstrated. Only the alongshore wind component is considered here, which is just one factor that impacts the coastal upwelling. Examining all the factors related to upwelling and sea surface temperature is avoided to concentrate on just the possible influence of large scale oscillations on the alongshore wind stress. The inertia of the ocean is large compared to that of the atmosphere so short pulses may not result in upwelling and the ocean's own internal forcing may dominate the signal. This work is meant to describe the ambient upwelling conditions but not the upwelling itself that also depends on other factors. Data is described in section 2, results are provided in section three, and a summary is given in section 4 .

\section{Data}

[4] Daily 10-m wind data is obtained from the National Center for Environmental Prediction's Climate Forecast System Reanalysis (CFSR) [Saha et al., 2010] from 1979 through 2009 . The horizontal grid spacing is $\sim 30 \mathrm{~km}$ at $30^{\circ} \mathrm{S}$ and there are 64 vertical levels, which is a higher resolution than previous reanalyses. For example, NCEPv2 is $\sim 240 \mathrm{~km}$ at $30^{\circ} \mathrm{S}$ and has 28 vertical levels [Kanamitsu et al., 2002]. A sufficiently high resolution is necessary to adequately resolve near-coast features. Low resolution tends to smooth out features, especially near sharp gradients in topography, diminishing values of the extrema [Mass et al., 2002]. After 1987 , wind speed over the ocean was regularly obtained from satellite scatterometer measurements and assimilated into the CFSR (details in Saha et al. [2010]). Using only the available satellite-derived wind also showed the same relationships between the large scale oscillations and the meridional wind as the CFSR, but the advantage of the CFSR is a more complete/integrated data set. Other fairly high resolution reanalyses such as MERRA [Rienecker et al., 2011] show results consistent with CFSR.

[5] Daily anomalies (departures from the 31-year average annual cycle) of the SLP and the meridional wind component are binned according to the indices and their average that is significantly different than zero is the final composite. There are several methods for determining significance. Standard statistical tests such as the $t$ test are often used to determine if the null hypothesis can be rejected in favor of the alternative hypothesis. In this case the null hypothesis is that the mean of the anomalies is zero and the alternative hypothesis is that the mean of the anomalies is different than zero. The $t$ test assumes that the sampled data is identically distributed and independent, which is not the case here since the data is autocorrelated. Thus, the standard $\mathrm{t}$ test is a permissive method because autocorrelation implies an underestimation of the variance from the sample that leads to a larger $t$ statistic and a higher rejection of the null hypothesis. A way to mitigate this problem employs a "variance inflation factor" that depends on the strength of autocorrelation [Wilks, 2006].

[6] A different technique to determine significance uses resampling methods also known as randomization tests, rerandomization tests, or Monte-Carlo tests. The basic idea is that artificial data sets are made by resampling from the original data set and the test statistic is computed from these artificial data sets. An advantage is that this method operates entirely on the data itself, so no assumptions of a parametric distribution need to be made. Within these resampling techniques is the bootstrap scheme that resamples from the original data giving equal probability to each observation with the same size as the original sample and is conducted with replacement. This resampling is repeated many times and the frequency distribution of these values is used to construct the test statistic that approximates the true sampling distribution of that test statistic. If zero lies in the tails of the distribution, the null hypothesis is rejected. Like the parametric counterparts, this test is not immune to serial correlation and becomes permissive [Zwiers, 1990]. A way to mitigate this problem is using a "moving block" bootstrap [e.g., Wilks, 1997]. The moving block bootstrap is the same as the normal bootstrap, but instead of resampling individual points, subsets of fixedlength consecutive data blocks are resampled. An appropriately chosen block length will be large enough that values separated by that time period will be independent. While selection of block length is still somewhat ad hoc and qualitative, a more quantitative method has been proposed by Wilks [1997]. Ultimately for this work, the moving block bootstrap is chosen to test for significance. Using Wilks [1997] as a guideline, a subset of 20 days is chosen for the moving block. Test statistics are created by resampling 1000 times. Using a $95 \%$ confidence level, if zero lies in the tails of the distribution, the anomaly is significantly different than zero.

[7] For the most part, there were only minor differences between the spring and summer conditions and the fall and winter conditions. ENSO in summer and AAO in spring contain only small areas of significant anomalies. For convention, a stronger (weaker) $\triangle \mathrm{SLP}_{\mathrm{y}}$ will mean a greater northward (southward) component, and upwelling favorable refers to stronger southerly wind, while upwelling unfavorable refers to weaker southerly wind. 

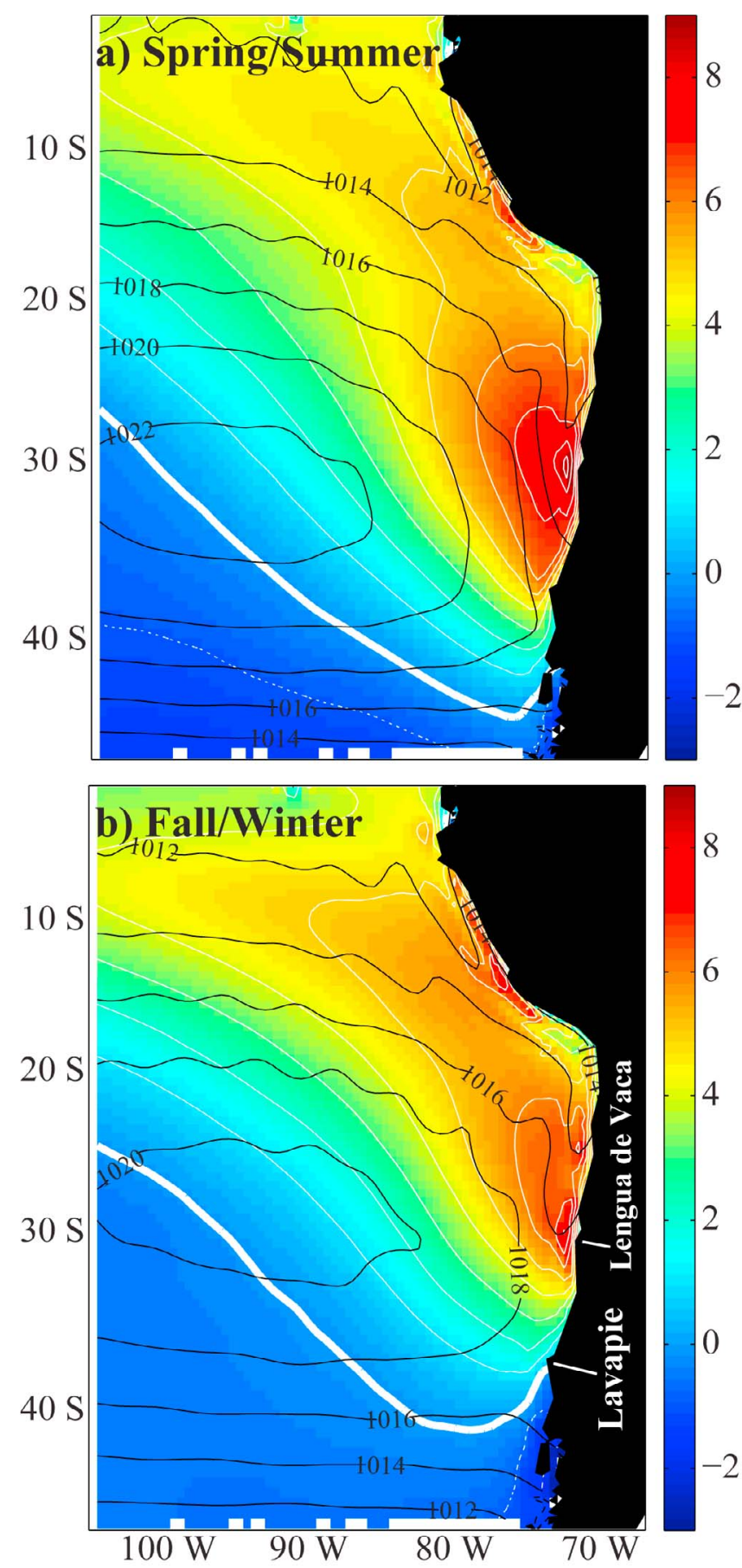

Figure 1. Mean daily SLP (hPa, black contours) and meridional wind ( $\mathrm{m} \mathrm{s}^{-1}$, color fill and white contours with the zero line in bold) for (a) spring/winter and (b) fall/winter.

[8] The index used to define ENSO is the Bivariate ENSO Time series where La Niña is $<-1$ and El Niño is $>1$ [Smith and Sardeshmukh, 2000]. The AAO is quantified using the Daily Southern Hemisphere Annular Mode Index [Nan and $L i, 2003]$, which is defined as the difference of the normalized zonal mean SLP between 40 and $70^{\circ} \mathrm{S}$. Since there is a trend toward the positive phase over recent decades [e.g., Thompson and Solomon, 2002], the linear trend has been removed. The MJO is quantified using the index of Wheeler and Hendon [2004] that describes the location (discretized into 8 phases) and strength (amplitude) of the convection. An active MJO is defined here as any time that the amplitude is above one.

\section{Results}

\subsection{Variability Over Different Time Scales}

[9] Alongshore wind may vary over a range of time scales and has a prominent annual cycle [Shaffer et al., 1999; Halpern et al., 2002]. Between spring/summer and fall/ spring, the center of the SEP anticyclone shifts north and south of $30^{\circ} \mathrm{S}$ (Figure 1). Mean daily southerly wind is present along the coast northward of Point Lavapie $\left(37^{\circ} \mathrm{S}\right)$ in the fall/winter and from even farther south in the spring/ summer. A maximum of the mean southerly wind near $30^{\circ} \mathrm{S}$ is present year-round. Diurnal variations are greatest from 20 to $30^{\circ} \mathrm{S}$ out to about $75^{\circ} \mathrm{W}$ and are largest during the warm periods of the year [Muñoz, 2008]. To investigate other time scales, the meridional wind at each grid point of the 6-hourly time series of CFSR data was bandpass filtered using a Butterworth filter for the synoptic, intraseasonal, annual, and interannual subranges. The synoptic range is defined as 2-16 days, which includes both the synoptic-scale transient time scale and also the slow synoptic processes time scale as used in other studies [e.g., Gulev et al., 2002]. The intraseasonal subrange is defined as 30-90 days, the annual subrange is defined as $335-395$ days, and the interannual subrange is defined as 2-7 years. The standard deviation of each of the bandpass-filtered time series is calculated to provide an estimate of the typical variation of each subrange (Figure 2). As expected, the synoptic subrange contains the greatest variability. Generally, the variability increases from smaller values in the subtropics to larger values southward, which is due to greater synoptic activity associated with midlatitude weather systems. However, the increase is not zonally symmetric because the largest values of the standard deviation on the synoptic scale tend to be near the coast and have an anomalous northward extension near the shore. The zonal asymmetry reflects the influence of the topography that effectively blocks much of the low-level zonal flow and is important in the formation of the alongshore low-level jet that often develops along the coast.

[10] The intraseasonal, annual, and interannual standard deviation of the meridional wind indicates that the largest fluctuations are centered near Point Lavapie $\left(37^{\circ} \mathrm{S}\right)$. Throughout the year north of about $30^{\circ} \mathrm{S}$ there are small changes in the alongshore wind compared to $30-40^{\circ} \mathrm{S}$ (Figure 1), resulting in a larger standard deviation of the annual cycle concentrated near Point Lavapie (Figure 2). For the intraseasonal subrange the greatest variability is also found near Lavapie, but it is less concentrated at the point and higher standard deviations than the annual cycle cover a broader area north and south of Point Lavapie. The magnitude of the interannual variation is less than the other time scales, but is also centered on Point Lavapie. Interestingly, interannual variability also shows a smaller, secondary maximum near Lengua de Vaca $\left(30^{\circ} \mathrm{S}\right)$. Variability of the coastal wind may be related to a shift and change in intensity of the SEP anticyclone, or it may be a result of more numerous cyclones that pass through the region due to a shift of storm tracks. Intraseasonal changes in the strength or position of the anticyclone or a shift of the storm tracks can be linked to 

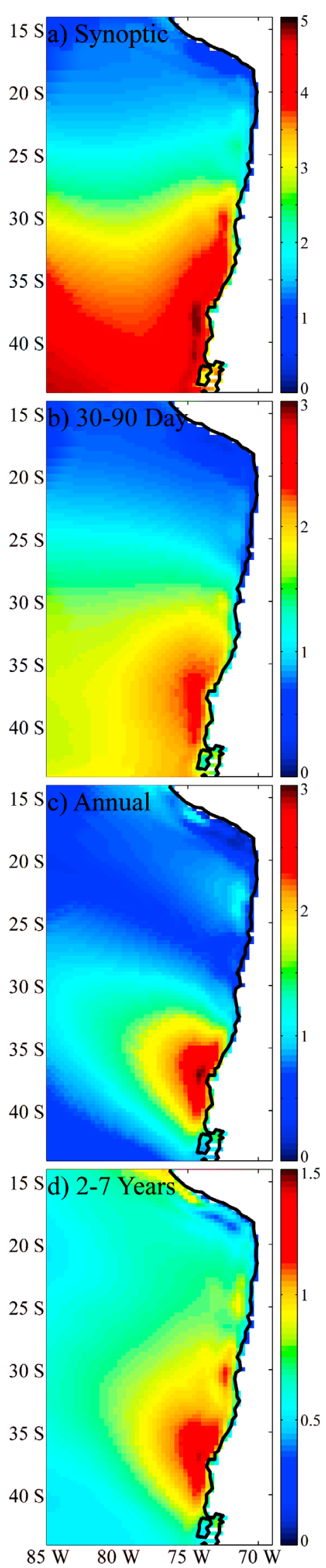

changes of the large scale circulation. It is within the context of the changes to the large scale oscillations represented by ENSO, AAO, and MJO that the alongshore winds on time scales longer than synoptic are addressed. The diagnosis not only includes changes to the mean state, but also changes in the distribution of the alongshore wind that reflect the modification of synoptic activity.

\subsection{Individual Oscillations}

\subsubsection{ENSO}

[11] ENSO is a slow oscillator that is marked by a shift in equatorial sea surface temperature and zonal SLP gradient that influences the Walker and Hadley circulations and thus modulates the strength of the SEP anticyclone. During La Niña (El Niño) the sea surface temperature in the Equatorial Pacific is cooler (warmer) than normal. Changes in the equatorial conditions are known to impact surface pressure and wind in the southeast Pacific [Aceituno, 1988] and much work has been done to understand the relationship between ENSO and precipitation in Chile [e.g., Rutllant and Fuenzalida, 1991; Montecinos and Aceituno, 2003]. Montecinos and Gomez [2010] demonstrated that the onset and end of the upwelling over south-central Chile changes such that there is a longer (shorter) upwelling season by an average of three weeks near $\sim 37^{\circ} \mathrm{S}$ during La Niña (El Niño). During El Niño the SEP anticyclone and $\triangle \mathrm{SLP}_{\mathrm{y}}$ are weaker and there is a blocking pattern over the Amundsen and Bellingshausen Sea. The meridional dipole in the surface circulation results in a higher frequency of midlatitude cyclones that pass through south central Chile, which was also found by Montecinos and Aceituno [2003].

[12] Composites of SLP and meridional wind (Figure 3) during La Niña (El Niño) show that there is a higher (lower) SLP over most of the domain, and the greatest anomalies of SLP are centered about $40^{\circ} \mathrm{S}$. Along most of the coast there are greater (smaller) SLP anomalies to the south leading to a stronger (weaker) $\Delta \mathrm{SLP}_{\mathrm{y}}$. The topography modulates the pressure perturbations since an enhanced or diminished $\triangle \mathrm{SLP}_{\mathrm{y}}$ results in coastal troughing or ridging, respectively [Muñoz and Garreaud, 2005]. During the spring and summer the magnitude of the anomalies in meridional wind reach up to $0.75 \mathrm{~m} \mathrm{~s}^{-1}$ and during the fall and winter they reach up to $1.5 \mathrm{~m} \mathrm{~s}^{-1}$. There are positive alongshore wind anomalies during La Niña when $\triangle \mathrm{SLP}_{\mathrm{y}}$ is greater and negative alongshore wind anomalies during El Niño when $\Delta \mathrm{SLP}_{\mathrm{y}}$ is weaker. The anomaly associated with the phase of ENSO (nor with the forthcoming other indices) is not overwhelmingly strong considering the standard deviation of daily wind speed near the coast at $35^{\circ} \mathrm{S}$ is $3.5 \mathrm{~m} \mathrm{~s}^{-1}$ [Garreaud and Muñoz, 2005]. However, it is significantly different than zero. While day-to-day variability dominates, there is up to $\sim 2 \mathrm{~m} \mathrm{~s}^{-1}$ difference of the mean alongshore wind at $35^{\circ} \mathrm{S}$ between La Niña and El Niño.

[13] Change of the mean alongshore wind is one of the most important factors, but an average does not reveal how the distribution changes. To understand how the large scale

Figure 2. Standard deviation of the (a) synoptic, (b) interseasonal, (c) annual, and (d) interannual (2-7 years) band passed filtered meridional component of the 10-m surface wind $\left(\mathrm{m} \mathrm{s}^{-1}\right)$ from the CFSR. Note the different color scales. 

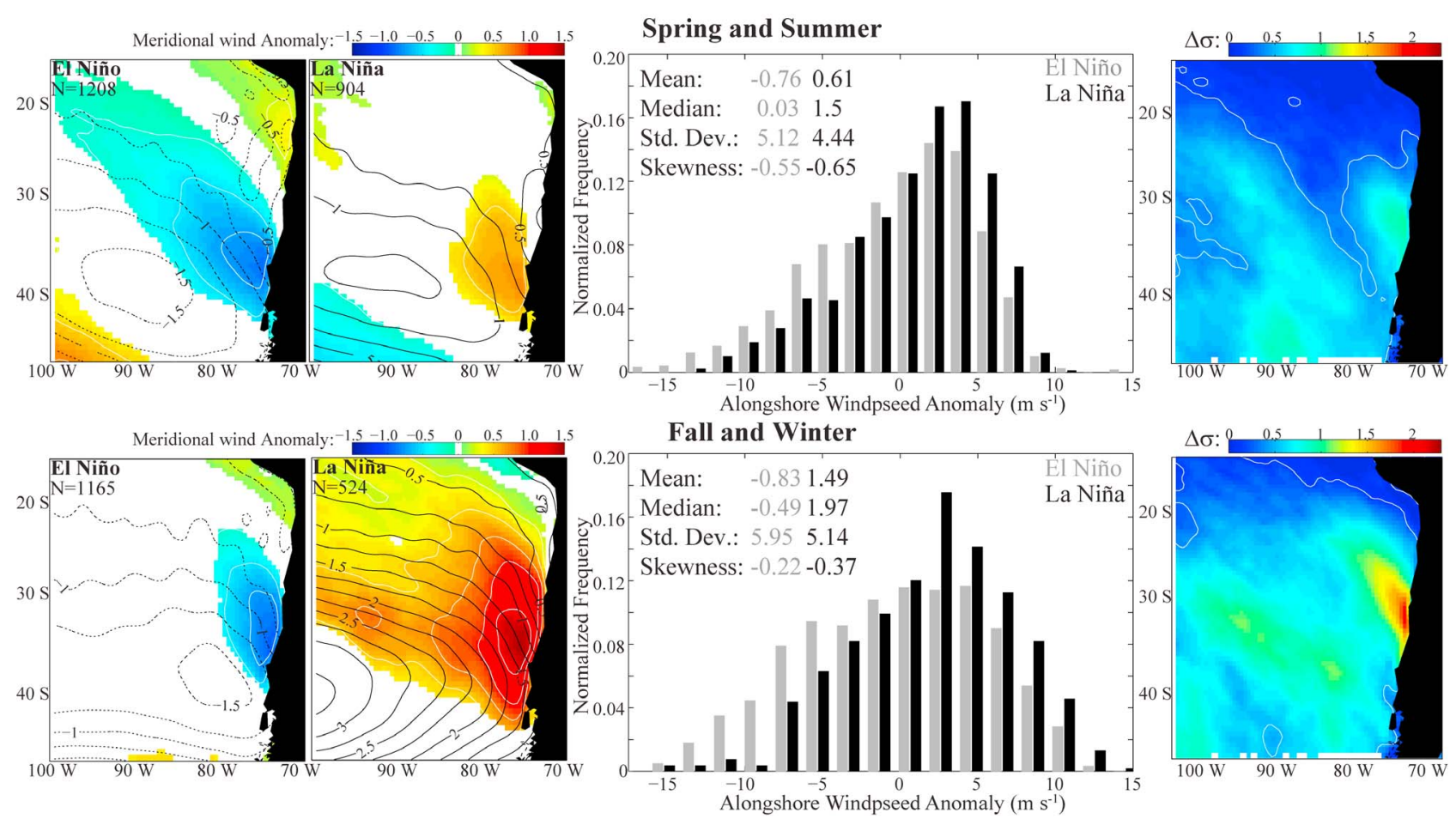

Figure 3. Diagnostics of ENSO. (left) The composites of SLP anomalies (hPa, black contours) and significant meridional wind anomalies $\left(\mathrm{m} \mathrm{s}^{-1}\right.$, color and white contours every $0.25 \mathrm{~m} \mathrm{~s}^{-1}$ ) binned according to the index indicated in each panel. (middle) The distribution of meridional wind anomalies $\left(\mathrm{m} \mathrm{s}^{-1}\right)$ at $35^{\circ} \mathrm{S}, 75^{\circ} \mathrm{W}$ for favorable upwelling conditions (black) and unfavorable upwelling conditions (gray). (right) The difference of standard deviation of the meridional wind $\left(\mathrm{m} \mathrm{s}^{-1}\right)$ between opposite phases. White line delineates significant from insignificant values. Conditions during spring and summer are on top while fall and winter are below. $\mathrm{N}$ is the number of days in each composite.

circulation impacts the distribution of the wind, a normalized histogram (rescaled so the total area is one) of the wind anomalies is constructed using the data at $35^{\circ} \mathrm{S}, 75^{\circ} \mathrm{W}$ since this is near the center of the greatest anomalies. For reference, the mean meridional wind speed during the spring and summer is $6.6 \mathrm{~m} \mathrm{~s}^{-1}$ and during the fall and winter is $3.1 \mathrm{~m} \mathrm{~s}^{-1}$. During spring and summer the distributions are similar but are offset from each other slightly and there is a difference of $0.7 \mathrm{~m} \mathrm{~s}^{-1}$ in the standard deviation. This indicates a modest change of the SEP anticyclone and to the storm tracks. During the fall and winter, the distributions are less skewed than in the spring and summer, and during La Niña the distribution is more clustered around the median. There are many more strong northerly wind anomalies during El Niño indicating the propensity for strong cyclones that move through the region during El Niño instead of a more persistent and stronger anticyclone during La Niña that is only occasionally interrupted by a cyclone.

[14] The standard deviation is an indication of the spread of the distribution and its difference between La Niña and El Niño represents a change in the variability linked to synoptic activity. If there is little change in the standard deviation, this suggests a simple shift of the distribution while the synoptic activity is about the same. The greatest differences of the standard deviation of the meridional wind between spring/summer and fall/winter are located north of the maximum mean anomaly, which is near the secondary maximum at $\sim 30^{\circ} \mathrm{S}$ seen in the 2-7 year standard deviation
(Figure 2d). An explanation for this is that north of the maximum mean anomaly is a fairly stable region that is normally removed from the greater synoptic variability to the south so it has a small standard deviation. Only when the anticyclone is weakened can storm tracks impact this far north. When the storm tracks are pushed northward of their climatological mean, this introduces much more variability to the otherwise stable conditions.

\subsubsection{AAO}

[15] Over the southern hemisphere, the leading empirical orthogonal function of SLP variability is an annular seesaw in SLP between Antarctica and the middle latitudes, referred to as the AAO or southern hemisphere annular mode. During a positive AAO, the SLP over Antarctica is weaker than normal [Nan and $L i, 2003$ ], and the composite during a positive AAO shows that the SLP over the SEP is stronger than normal (Figure 4). North of $40^{\circ} \mathrm{S}$ is a stronger $\Delta \mathrm{SLP}_{\mathrm{y}}$ near the coast of Chile that is associated with greater southerly wind and a maximum meridional wind anomaly reaching up to $1.0 \mathrm{~m} \mathrm{~s}^{-1}$. The greatest anomalies of meridional wind are near the location of the greatest standard deviation at the intraseasonal and annual subranges (Figure 2). During a negative AAO, the opposite scenario is established. Because the AAO is defined using the SLP anomaly, the link between the AAO, SLP, and alongshore wind is straightforward.

[16] During the spring and summer the mean of the distribution between the negative and positive phase of the AAO shifts, but its shape remains similar with only a slight 

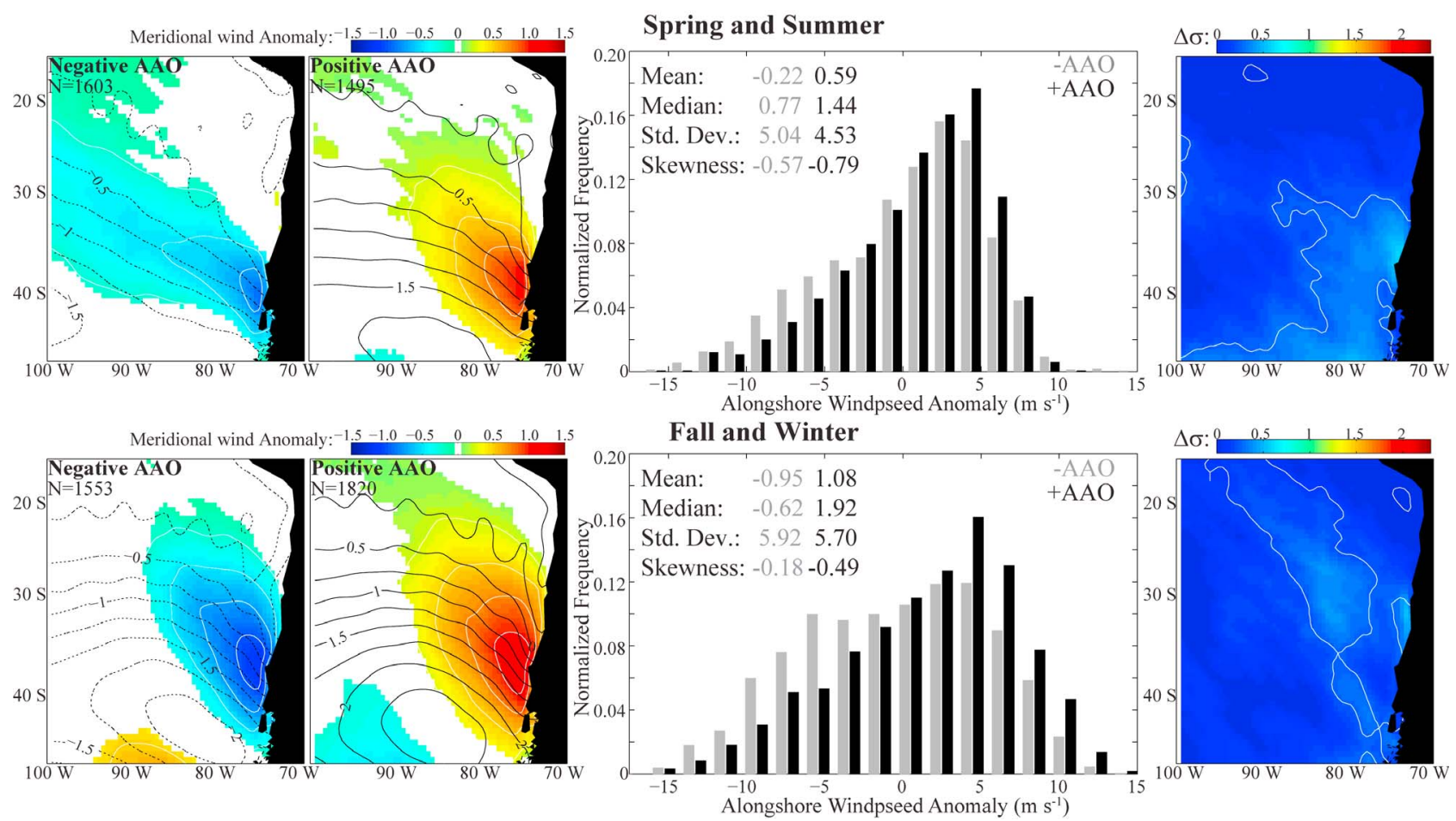

Figure 4. As Figure 3, but for AAO.

broadening of the distribution. For fall and winter the distribution is more skewed for the positive, upwelling-favorable phase of the AAO. Despite the change in shape of the distribution, the standard deviation during fall/winter does not change significantly near Lavapie, but it does change near the coast north of Lavapie and south of $30^{\circ} \mathrm{S}$ and also in a swath extended to the northwest offshore. There are significant changes to the standard deviation in spring/summer off of Lavapie and to the south.

\subsubsection{MJO}

[17] An active MJO represents the often irregular eastward propagation of a large convective area along the equator with a phase of 30-60 days. Hormazabal et al. [2002] speculated that the MJO modulates the strength of the SEP anticyclone through atmospheric equatorial Kelvin waves which generate poleward-propagating waves trapped by the elevated coastal topography and through (standing) Rossby wave trains from the western tropical Pacific to subtropical latitudes off Chile. Maximum intraseasonal correlations between northerly wind anomalies off central Chile at $30^{\circ} \mathrm{S}, 72^{\circ} \mathrm{W}$ were found after typically a zero or one week lag of the easterly wind anomaly in the central equatorial Pacific in austral winter.

[18] Composites of each phase in the Wheeler and Hendon [2004] index (Figure 5) reveal the teleconnection to the SEP. In phases 2 and 3 when the equatorial convection is over the Indian Ocean, there are only small pockets of significant changes to the meridional wind. As the equatorial convection moves eastward over Indonesia and the MJO index progresses through phases 4,5 , and 6 , the surface pressure over the SEP strengthens and positive wind anomalies develop along the northern coast of Chile. The center of the anomaly moves southward until reaching near Lavapie in phase 6 when the equatorial convection is over the western Pacific. Negative anomalies develop in northern Chile in phase 7 (equatorial convection near the dateline), which strengthen and move southward toward Lavapie as the MJO progresses through phases 8 and 1 (convection over the central Pacific Ocean). These findings are consistent with Barrett et al. [2012] who examined the relationship of winter (May-August) precipitation in Chile with the anomalous circulation over the SEP associated with the MJO. Since the greatest anomalies over the SEP occurred during phases 4, 5, and 6 (MJO456) and phases 7, 8 and 1 (MJO781), these will be grouped together to diagnose the impact of the MJO on the SEP.

[19] During MJO456 (MJO781) the SEP anticyclone strengthens (weakens) while the subtropical SLP weakens (strengthens), leading to a stronger (weaker) $\triangle \mathrm{SLP}_{\mathrm{y}}$ (Figure 6). Magnitudes of the anomalies are similar between spring/ summer and fall/winter and are comparable to those of the ENSO and AAO. The anomalies are near the greatest anomalies of the standard deviation within the intraseasonal subrange, but extend farther into northern Chile. Of the three indices, this one tends to have the greatest impact on the upwelling favorable wind for north-central Chile. The distributions are offset but the standard deviation is not significantly different in spring and summer, however there is a difference in the skewness of the distribution. During the fall and winter there is a significant difference in the standard deviation that extends in a narrow swath from the coast between 30 and $40^{\circ} \mathrm{S}$ toward the northwest.

\subsection{Combined Oscillations}

[20] If the indices that represent the three oscillations are independent of each other, one would expect to see constructive or destructive behavior. For example, a positive AAO during La Niña is likely to be reinforced and result in a stronger $\triangle \mathrm{SLP}_{\mathrm{y}}$ near the coast that drives stronger wind. Interdependence of the indices has been proposed, such as 


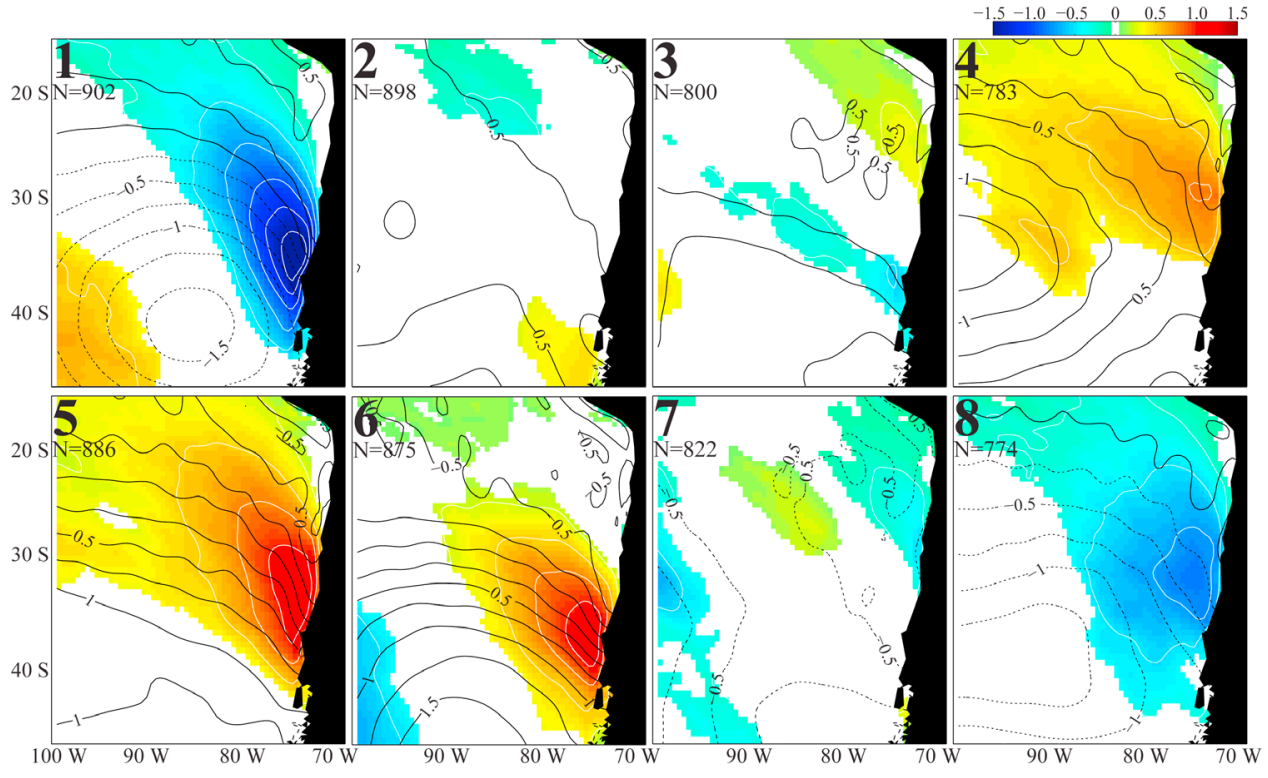

Figure 5. Composites of SLP anomalies ( $\mathrm{hPa}$, black contours) and significant meridional wind anomalies $\left(\mathrm{m} \mathrm{s}^{-1}\right.$, color and white contours every $0.25 \mathrm{~m} \mathrm{~s}^{-1}$ ) binned according to the phase of the MJO that is indicated in each panel. $\mathrm{N}$ is the number of days in each composite.

Carvalho et al. [2005] who found $25 \%$ of the AAO variance linearly relates to the state of ENSO. Given the similar time scales of the AAO and MJO, Matthews and Meredith [2004] suggested that 7 days after convection in the equatorial Indian Ocean the AAO reaches a maximum. Conversely, Pohl et al. [2010] argued that at intraseasonal time scales both the AAO and ENSO and also the AAO and MJO are not unambiguously related. El Niño (La Niña) conditions are associated with faster (slower) eastward propagation of the MJO convective complex and shorter (longer) lifetimes during the equinoctial seasons (March-May and OctoberDecember) [Pohl and Matthews, 2007].

[21] Regardless of the fundamental interrelations, it is practical to know how these potentially relate to the coastal wind. Destructive combinations (opposing signs of the wind anomaly) have few areas of significant anomalies so are not shown. However, this is still a significant finding since this indicates that the opposing signals among the oscillations may
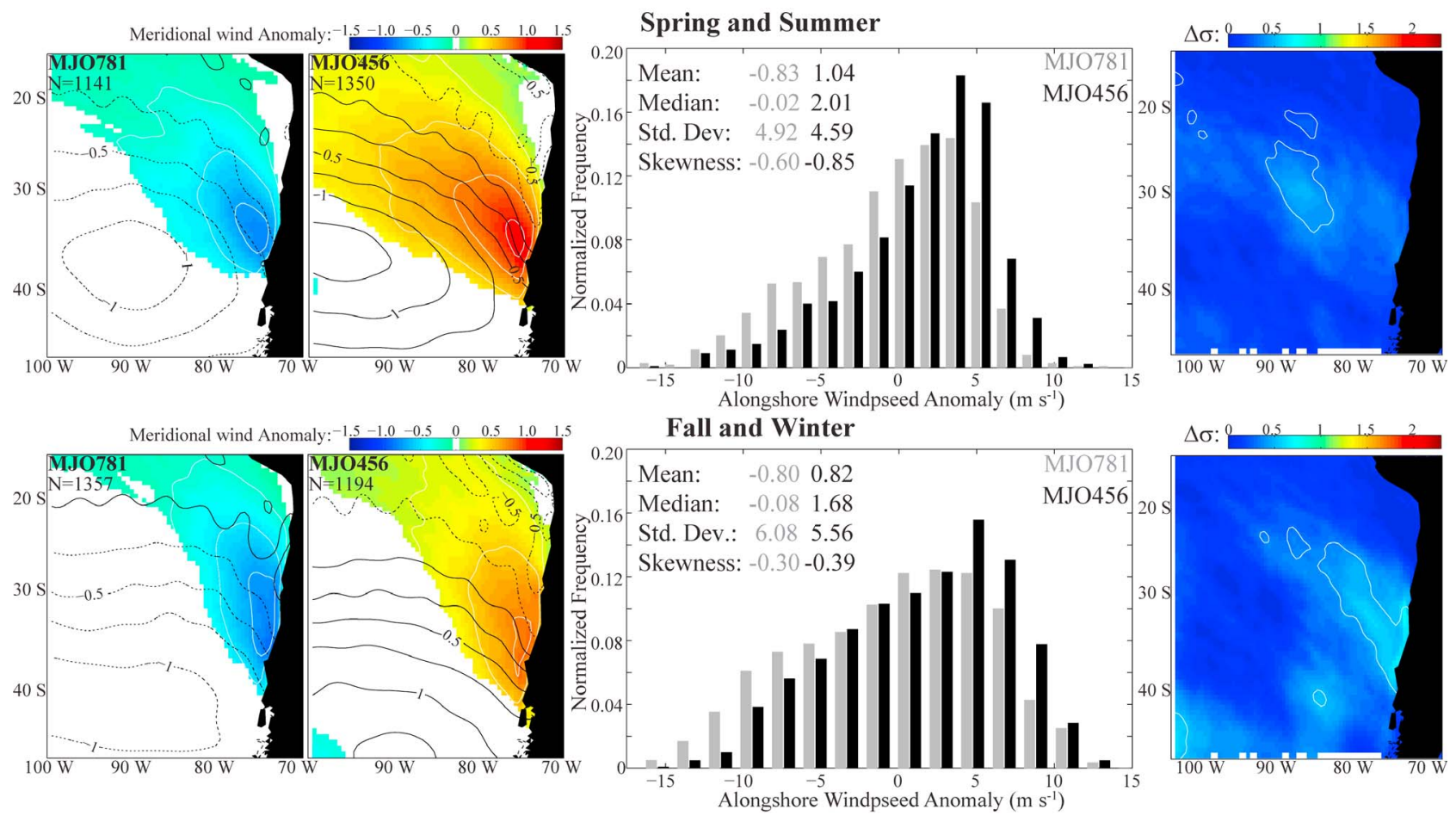

Figure 6. As Figure 3 but for MJO. 

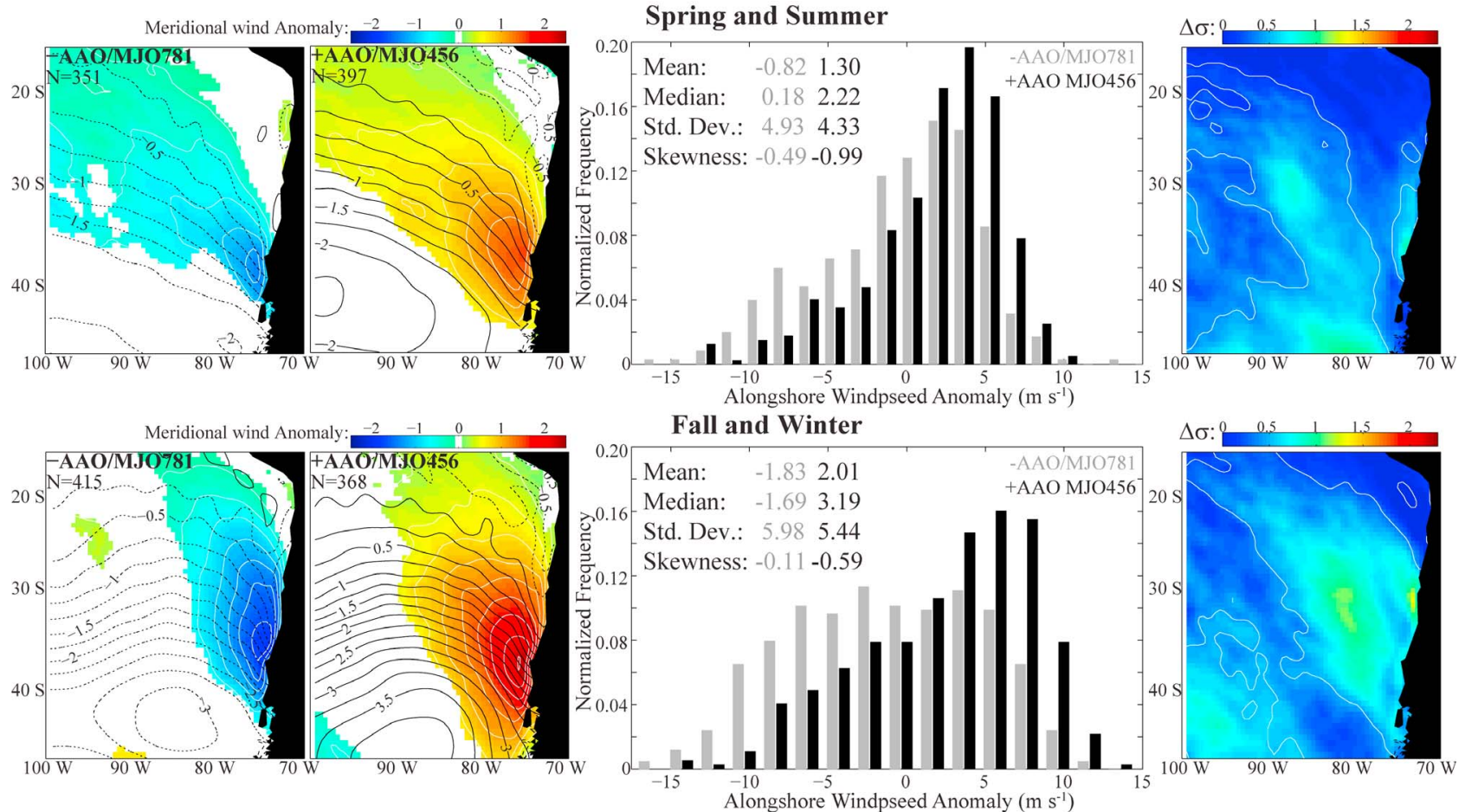

Figure 7. As Figure 3, but for AAO/MJO.

effectively cancel each other. Constructive composites (same sign of the wind anomaly) during spring/summer and fall/ winter for $\mathrm{AAO} / \mathrm{MJO}$, ENSO/MJO, and $\mathrm{AAO} / \mathrm{ENSO}$ are shown in Figures 7, 8, and 9, respectively. Each combination demonstrates significant anomalies over a much greater area, especially during fall/winter when much more of the coastline is near a significant anomaly. Their extrema are greater than that of each component alone, but they are not completely additive. For the alongshore wind at $35^{\circ} \mathrm{S}, 75^{\circ} \mathrm{W}$ the ratio of the multiple index composites to the sum of the individual composites is $0.70-0.95$.
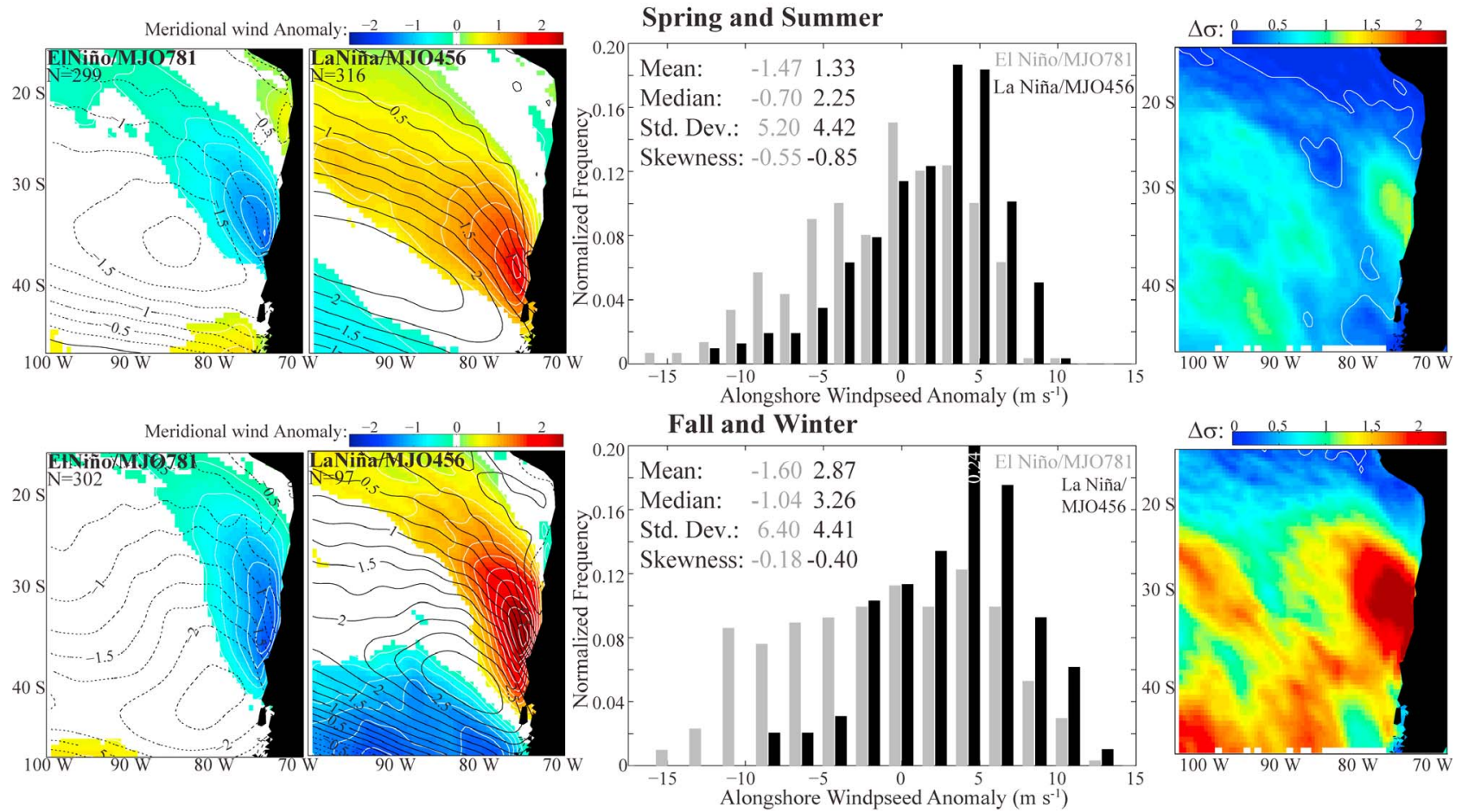

Figure 8. As Figure 3, but for ENSO/MJO. 

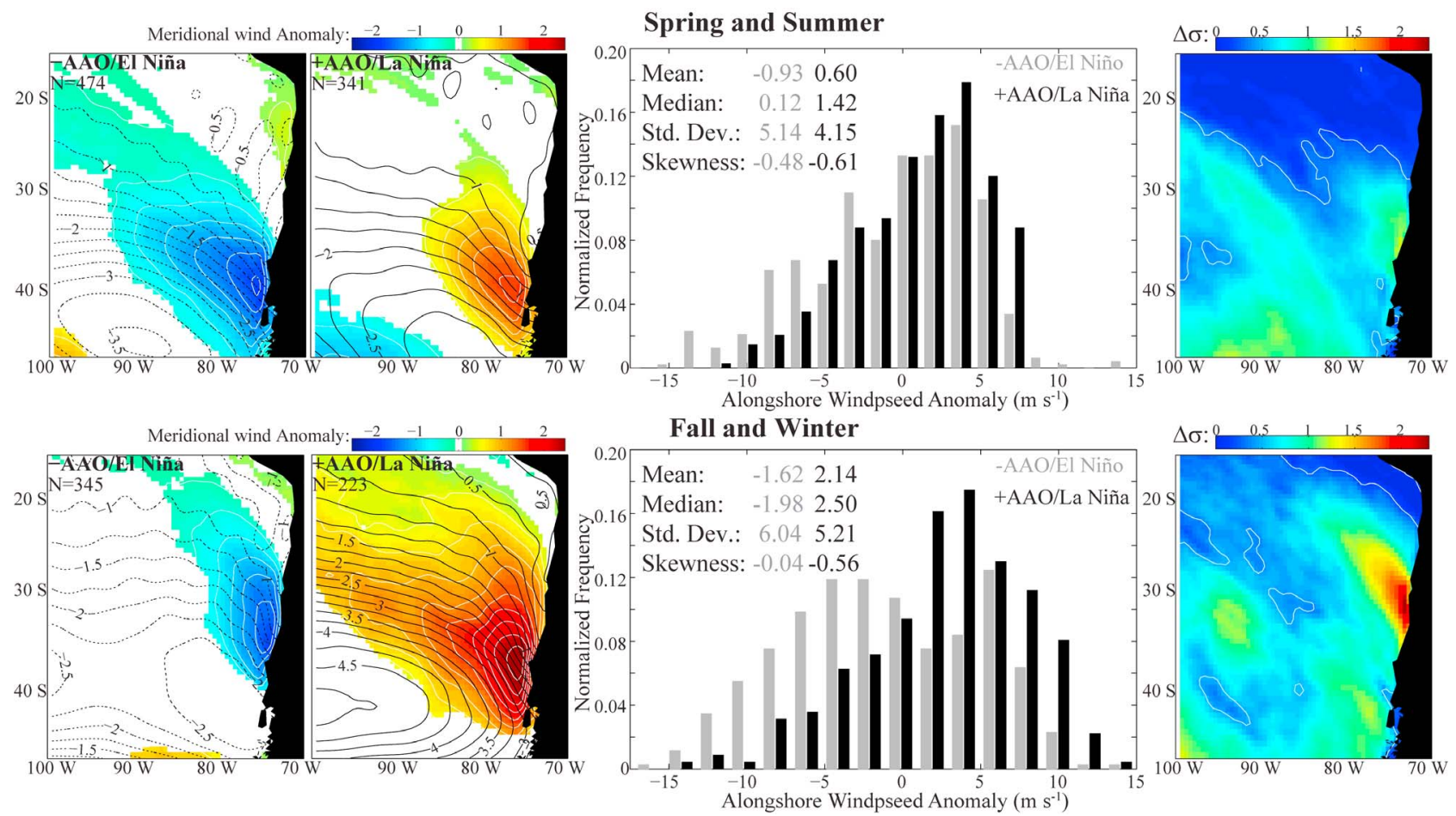

Figure 9. As Figure 3, but for AAO/ENSO.

[22] Changes to the distribution of the wind between favorable and unfavorable composites are more evident than the individual composites. Generally, the upwelling-favorable combinations have a tighter cluster around positive anomalies with a tail toward negative anomalies, while the upwellingunfavorable combinations are broader and more normally distributed. This again reflects the difference between a stable and strong anticyclone during the upwelling-favorable conditions and a weaker anticyclone accompanied with more synoptic activity during upwelling-unfavorable conditions. For the individual phases of AAO and MJO (Figures 4 and 6), the difference in the standard deviation between favorable and unfavorable states of the oscillation is small and the significant values cover a relatively small area. Their combined indices (Figure 7) demonstrate larger changes to the standard deviation between favorable and unfavorable states with significant values covering a larger area.

[23] During the constructive ENSO and MJO pairs (Figure 8), the difference in the variability is the greatest, especially toward the north $\left(\sim 30^{\circ} \mathrm{S}\right)$ in fall/winter. The difference in the distribution during fall/winter is marked. La Niña and MJO456 are associated with a strong and persistent anticyclone (few cyclones), while El Niño and MJO781 have a much broader distribution with many days exhibiting strong wind anomalies from the north, associated with increased cyclone activity. In fact, Juliá et al. [2012] found the greatest probability for precipitation events at $30^{\circ} \mathrm{S}$ coincide with El Niño at the same time as an MJO in phase 7, 8, 1, or 2 . During the negative phase of the AAO and El Niño in fall/ winter (Figure 9), the distribution is actually bimodal with peaks around -4 and 6 . The reason for this is unclear, but it is not due to a small sample since there are 345 days under these conditions.
[24] Similar to Garreaud and Falvey [2009] who found that monthly $\triangle \mathrm{SLP}_{\mathrm{y}}$ and alongshore wind correlated well month-to-month, for each individual index and combined indices for spring/summer and fall/winter the $\triangle \mathrm{SLP}_{\mathrm{y}}$ is calculated along $74^{\circ} \mathrm{W}$ between 30 and $40^{\circ} \mathrm{S}$ and the alongshore wind anomaly is taken at $35^{\circ} \mathrm{S}, 74^{\circ} \mathrm{W}$. The linear relationship of Garreaud and Falvey [2009] holds with a regression that has a slope of $1.2 \mathrm{~m} \mathrm{~s}^{-1} \mathrm{hPa}^{-1}$ (Figure 10). This also depicts the transition from the greatest anomalies in the fall/winter for combined indices to the smallest anomalies in the spring/ summer for a single index.

\section{Conclusions}

[25] To elucidate on the relationship between the upwellingfavorable wind along the Chilean coast and the major oscillations over the SEP (ENSO, AAO, and MJO), composites of daily SLP and meridional $10-\mathrm{m}$ wind anomalies were constructed based on three decades of CFSR data which resolves the coastal features better than previous, coarser analysis. Associated with each index are changes in $\triangle$ SLP $_{\mathrm{y}}$ near the coast and the alongshore wind, which diminishes offshore. Consistent with the greater standard deviation present near Point Lavapie $\left(37^{\circ} \mathrm{S}\right)$ in the intraseasonal and interannual time scales, the location of the anomalies associated with ENSO, AAO, and MJO are also near Point Lavapie. Standard deviation in the synoptic subrange is much greater and extends farther northward near the coast. Alongshore wind anomalies for each index reach $\sim 1 \mathrm{~m} \mathrm{~s}^{-1}$, which is not particularly great given a standard deviation of daily wind at $35^{\circ} \mathrm{S}, 74^{\circ} \mathrm{W}$ of $3.5 \mathrm{~m} \mathrm{~s}^{-1}$ that is driven mainly by synoptic activity [Garreaud and Muñoz, 2005]. Nevertheless, the anomalies are significant and extend over much of the central 


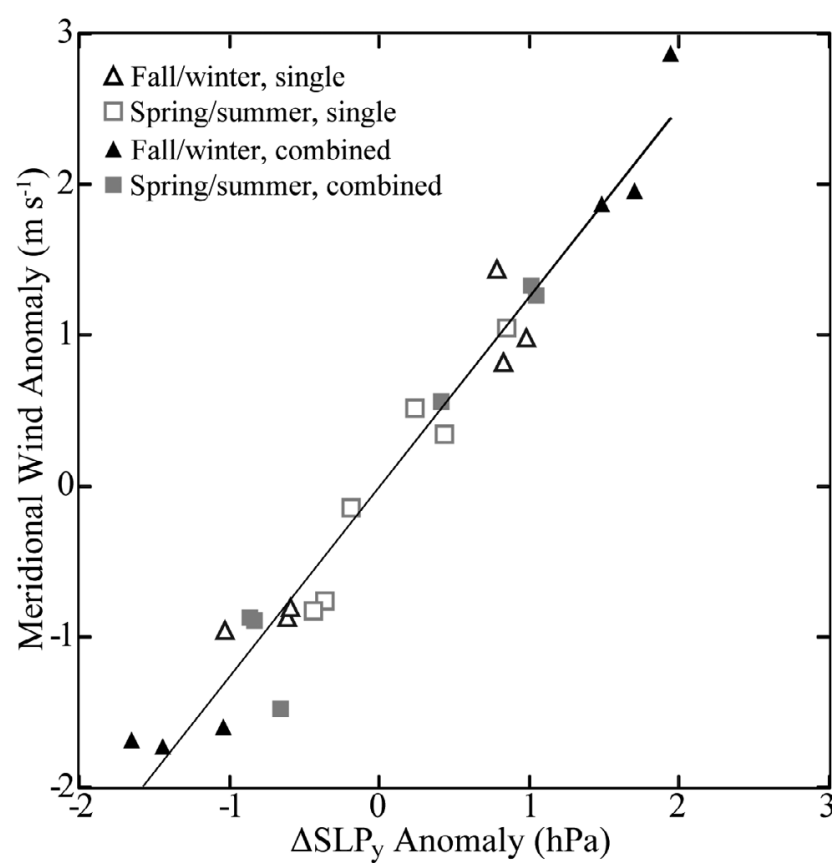

Figure 10. The $\triangle \mathrm{SLP}_{\mathrm{y}}(\mathrm{hPa})$ along $74^{\circ} \mathrm{W}$ between 30 and $40^{\circ} \mathrm{S}$ and meridional wind anomaly $\left(\mathrm{m} \mathrm{s}^{-1}\right)$ at $35^{\circ} \mathrm{S}, 74^{\circ} \mathrm{W}$ for each index (open symbols) and the constructive combinations (closed symbols) for fall and winter (black triangle) and spring and summer (gray square). Black line indicates the linear regression of all points.

Chilean coastline. Synoptic variability dominates the day-today alongshore wind, but the synoptic activity, background $\triangle \mathrm{SLP}_{\mathrm{y}}$, and alongshore wind are modified during an active ENSO, AAO, or MJO so the synoptic variability is centered on a mean $\pm 1 \mathrm{~m} \mathrm{~s}^{-1}$ different than the long-term average. Some other key findings are listed: (1) stronger upwelling-favorable wind during La Niña, positive AAO, and MJO456; (2) weaker upwelling-favorable wind during El Niño, negative AAO, and MJO781; (3) anomalies generally greater during fall and winter than in spring and summer; (4) large scale oscillations represented by the indices act constructively (up to $2 \mathrm{~m} \mathrm{~s}^{-1}$ anomalies) and destructively (effectively canceling any significant signal); (5) upwelling-favorable conditions tend to be clustered around positive anomalies, skewed toward negative anomalies, and have a smaller standard deviation than unfavorable conditions that are more normally distributed, representing greater synoptic activity; (6) greatest difference in the standard deviation between stronger and weaker coastal wind for ENSO is north of the maximum anomaly, representing the shift of storm tracks; (7) the change of standard deviation between individual phases of AAO and MJO has fewer significant differences than ENSO, but together these have larger differences especially in fall/winter; (8) the MJO has the greatest impact for north-central Chile throughout the year except for La Niña in the fall/winter; (9) linear relationship between alongshore wind and $\Delta \mathrm{SLP}_{\mathrm{y}}$ is similar to Garreaud and Falvey [2009] and shows the range of impact from small changes for a single index during spring/summer to large changes for constructive indices during fall/winter.
[26] Only the alongshore wind conducive to offshore Ekman transport is examined here, which is just one component that impacts upwelling and the sea surface temperature. Other mechanisms include Ekman pumping, air-sea exchange through heat flux (latent and sensible), radiation, vertical mixing in the ocean mixed layer, and internal ocean dynamics. To avoid this complexity, the focus here is kept on quantifying the significant alongshore wind anomalies that are linked to changes in the large scale circulation.

[27] Acknowledgments. I thank the three reviewers whose comments improved the final version of the manuscript. This work was supported by FONDECYT 3110100.

\section{References}

Aceituno, P. (1988), On the functioning of the southern oscillation in the South American sector. Part I: Surface Climate, Mon. Weather Rev., 116, 505-524, doi:10.1175/1520-0493(1988)116<0505:OTFOTS> 2.0.CO;2.

Barrett, B. S., J. F. Carrasco, and A. P. Testino (2012), Madden-Julian Oscillation (MJO) modulation of atmospheric circulation and Chilean winter precipitation, J. Clim., 25, 1678-1688, doi:10.1175/JCLI-D-1100216.1 .

Carvalho, L. M. V., C. Jones, and T. Ambrizzi (2005), Opposite phases of the Antarctic Oscillation and relationships with intraseasonal to interannual activity in the tropics during the austral summer, J. Clim., 18, 702-718, doi:10.1175/JCLI-3284.1.

Garreaud, R., and M. Falvey (2009), The coastal winds off western subtropical South America in future climate scenarios, Int. J. Climatol., 29, 543-554, doi:10.1002/joc. 1716.

Garreaud, R. D., and R. Muñoz (2005), The low-level jet off the subtropical west coast of South America: Structure and variability, Mon. Weather Rev., 133, 2246-2261, doi:10.1175/MWR2972.1.

Gulev, S. K., T. Jung, and E. Ruprecht (2002), Climatology and interannual variability in the intensity of synoptic-scale processes in the North Atlantic from the NCEP-NCAR reanalysis data, J. Clim., 15, 809-828, doi:10.1175/1520-0442(2002)015<0809:CAIVIT >2.0.CO;2.

Halpern, D., et al. (2002), An atlas of monthly mean distributions of SSMI wind speed, AVHRR sea surface temperature, TMI sea surface temperature, QuikSCAT ocean vector wind, SeaWiFS Chlorophyll-a, and TOPEX/POSEIDON sea surface topography during 2001, JPL Publ. 02-23, Jet Propul. Lab., NASA, Pasadena, Calif.

Hormazabal, S., G. Shaffer, and O. Pizarro (2002), Tropical Pacific control of intraseasonal oscillations off Chile by way of oceanic and atmospheric pathways, Geophys. Res. Lett., 29(6), 1081, doi:10.1029/2001GL013481.

Juliá, C., D. A. Rahn, and J. A. Rutllant (2012), Assessing the influence of the MJO on strong precipitation events in subtropical, semi-arid northcentral Chile $\left(30^{\circ} \mathrm{S}\right), \mathrm{J}$. Clim., in press.

Kanamitsu, M., W. Ebisuzaki, J. Woollen, S.-K. Yang, J. J. Hnilo, M. Fiorino, and G. L. Potter (2002), NCEP-DOE AMIP-II reanalysis (R-2), Bull. Am. Meteorol. Soc., 83, 1631-1643, doi:10.1175/BAMS-83-11-1631.

Mass, C. F., D. Ovens, K. Westrick, and B. A. Colle (2002), Does increasing horizontal resolution produce more skillful forecasts?, Bull. Am. Meteorol. Soc., 83, 407-430, doi:10.1175/1520-0477(2002)083<0407: DIHRPM $>2.3 . \mathrm{CO} ; 2$.

Matthews, A. F., and M. P. Meredith (2004), Variability of Antarctic circumpolar transport and the Southern Annular Mode associated with the Madden-Julian Oscillation, Geophys. Res. Lett., 31, L24312, doi:10.1029/2004GL021666.

Montecinos, A., and P. Aceituno (2003), Seaonality of the ENSO-related rainfall variability in central Chile and associated circulation anomalies, J. Clim. 16, 281-296, doi:10.1175/1520-0442(2003)016<0281:SOTERR $>2.0$.CO;2.

Montecinos, A., and F. Gomez (2010), ENSO modulation of the upwelling season off southern-central Chile, Geophys. Res. Lett., 37, L02708, doi:10.1029/2009GL041739.

Muñoz, R. C. (2008), Diurnal cycle of surface winds over the subtropical southeast Pacific, J. Geophys. Res., 113, D13107, doi:10.1029/ 2008JD009957.

Muñoz, R. C., and R. D. Garreaud (2005), Dynamics of the low-level jet off the west coast of subtropical South America, Mon. Weather Rev., 133, 3661-3677, doi:10.1175/MWR3074.1.

Nan, S., and J. Li (2003), The relationship between summer precipitation in the Yangtze River valley and the previous Southern Hemisphere Annular Mode, Geophys. Res. Lett., 30(24), 2266, doi:10.1029/2003GL018381. 
Pohl, B., and A. J. Matthews (2007), Observed changes in the lifetime and amplitude of the Madden-Julian Oscillation associated with interannual ENSO sea surface temperature anomalies, J. Clim., 20, 2659-2674, doi:10.1175/JCLI4230.1.

Pohl, B., N. Fauchereau, C. J. C. Reason, and M. Rouault (2010), Relationships between the Antarctic Oscillation, the Madden-Julian Oscillation, and ENSO, and consequences for rainfall analysis, J. Clim., 23, 238-254, doi:10.1175/2009JCLI2443.1.

Renault, L., B. Dewitte, M. Falvey, R. Garreaud, V. Echevin, and F. Bonjean (2009), Impact of atmospheric coastal jet off central Chile on sea surface temperature from satellite observations (2000-2007), J. Geophys. Res. 114, C08006, doi:10.1029/2008JC005083.

Rienecker, M. M., et al. (2011), MERRA-NASA's modern-era retrospective analysis for research and application, J. Clim., 24, 3624-3648, doi:10.1175/JCLI-D-11-00015.1.

Rutllant, J., and H. Fuenzalida (1991), Synoptic aspects of the central Chile rainfall variability associated with the Southern Oscillation, Int. J. Climatol., 11, 63-76, doi:10.1002/joc.3370110105.

Rutllant, J. A., B. Rosenbluth, and S. Hormazabal (2004), Intraseasonal variability of wind-forced coastal upwelling off central Chile $\left(30^{\circ} \mathrm{S}\right)$, Cont. Shelf Res., 24, 789-804, doi:10.1016/j.csr.2004.02.004.

Saha, S., et al. (2010), The NCEP Climate Forecast System Reanalysis, Bull. Am. Meteorol. Soc., 91, 1015-1057, doi:10.1175/2010BAMS3001.1.
Shaffer, G., S. Hormazabal, O. Pizarro, and S. Salinas (1999), Seasonal and interannual variability of currents and temperature off central Chile, J. Geophys. Res., 104, 29,951-29,961, doi:10.1029/1999JC900253.

Smith, C. A., and P. D. Sardeshmukh (2000), The effect of ENSO on the intraseasonal variance of surface temperatures in winter, Int. J. Climatol., 20, 1543-1557, doi:10.1002/1097-0088(20001115)20:13<1543::AIDJOC $579>3.0 . \mathrm{CO} ; 2-\mathrm{A}$

Thompson, D. W. J., and S. Solomon (2002), Interpretation of recent southern hemisphere climate change, Science, 296, 895-899, doi:10.1126/ science. 1069270 .

Wheeler, M. C., and H. H. Hendon (2004), An all-season real-time multivariate MJO Index: Development of an Index for Monitoring and Prediction, Mon. Weather Rev., 132, 1917-1932, doi:10.1175/1520-0493(2004) 132<1917:AARMMI>2.0.CO;2.

Wilks, D. S. (1997), Resampling hypothesis tests for autocorrelated fields, J. Clim , 10, 65-82, doi:10.1175/1520-0442(1997)010<0065:RHTFAF $>$ 2.0.CO;2.

Wilks, D. S. (2006), Statistical Methods in the Atmospheric Sciences, 2nd ed., Int. Geophys. Ser., vol. 91. 627 pp., Academic, Amsterdam.

Zwiers, F. W. (1990), The effect of serial correlation on statistical inferences made with resampling procedures, J. Clim., 3, 1452-1461, doi:10.1175/1520-0442(1990)003<1452:TEOSCO >2.0.CO;2. 